\title{
DESIGUALDADES SOCIAIS E ESCOLARES, FORMAÇÃO E POLÍTICAS PÚBLICAS: COMPROMISSOS E INTERESSES NO CAMPO DA EDUCAÇÃO
}

\section{INÉGALITÉS SOCIALES ET SCOLAIRES, FORMATION ET POLITIQUES PUBLIQUES: ENGAGEMENTS ET INTÉRÊTS DANS LE DOMAINE DE L'ÉDUCATION}

No Brasil, mais que outros países da América do Sul, a escola é um produto social desigualmente distribuído, seja pelas diferentes formas de absorção de categorias e grupos (classe, gênero, etnia, território, região), seja pelo tipo de rede escolar frequentado (público ou privado), constituindo, historicamente, um sistema educativo dualista e seletivo. Como disse Cristovam Buarque ${ }^{1}$, a escola brasileira é um funil de exclusão para a maioria da população brasileira, de modo que, apesar do desenvolvimento econômico e social dos últimos dez anos, o Brasil ainda esbarra em dois muros: a desigualdade que divide o país internamente e o atraso que o separa do resto do mundo desenvolvido. Esse fosso cultural e educacional que cria desigualdades dentro e para além das fronteiras nacionais decorre não só do longo e complexo processo de colonização e de desenvolvimento do Brasil, da concepção tradicional de educação aqui instaurada, mas, sobretudo, do tardio movimento de democratização da escola. 
Diferentemente da maioria dos países europeus, que universalizaram seus sistemas públicos de ensino durante o século XIX, no Brasil, os primeiros movimentos em benefício de um sistema público de educação datam dos anos de 1930; até então a educação e a escola eram assunto quase exclusivo da Igreja Católica.

Foi na década de 1920-1930, com a criação da Associação Brasileira de Educação $(\mathrm{ABE})$ e, particularmente com a publicação do Manifesto dos Pioneiros da Escola Nova em 1932, que se configurou no país um forte movimento de educadores em defesa da constituição de um sistema público de educação como resposta às demandas sociais crescentes. Esse manifesto expressa a introdução do pensamento pedagógico liberal entre os educadores brasileiros e levanta o debate, pela primeira vez entre nós, sobre a universalização (democratização) da escola, portadora de uma função eminentemente social e pública, portanto, de responsabilidade do Estado. Ao mesmo tempo, este movimento arrasta consigo as ideias pedagógicas inspiradas nos métodos ativos, estabelecendo um contraponto importante ao método tradicional de ensino até então empregado pelas escolas ligadas à Igreja.

Entretanto, as propostas concretas sugeridas pelo Manifesto sucumbiram frente às Reformas do Ensino promovidas pelos ministros Francisco Campos (1931) e Gustavo Capanema (19421946), as quais reforçaram o caráter elitista e dualista da escolarização na medida em que restabeleceram o ensino religioso nas escolas públicas primárias, organizaram o Ensino Médio voltado às elites e desenvolveram políticas de formação industrial e comercial para os trabalhadores independentemente dos demais níveis e modalidades de ensino.

Apesar de amadurecido o debate sobre a educação pública, universal e financiada pelo Estado e de haverem condições para a 
efetivação da escola moderna em nosso país, os interesses político-econômicos e corporativos do Estado não possibilitaram a realização de tal projeto, ficando a escola pública restrita aos filhos das elites dominantes e parcelas da classe média, enquanto a classe trabalhadora era conduzida à formação profissional, por meio de políticas especificamente voltadas à qualificação da mão de obra industrial $^{2}$.

As ideias renovadoras postuladas pelos "pioneiros" conquistaram hegemonia nas décadas seguintes ${ }^{3}$, atravessando o debate em torno da promulgação da LDB - Lei de Diretrizes e Bases da Educação Nacional, primeira legislação completa sobre educação no Brasil, datada de 1962. Mas embora esta lei tenha reforçado a escola pública no plano legislativo, isso não levou a grandes mudanças no plano prático, uma vez que as camadas desfavorecidas e zonas rurais permaneceram afastadas do processo de escolarização, de tal maneira que temos, emblematicamente, ao longo dos anos 1960 e 1970, grandes campanhas de massa em prol da alfabetização de adultos no país.

Fruto de intensos debates no seio do movimento dos educadores, a LDB de 1996 resulta, finalmente, de uma emenda do deputado Darci Ribeiro, de caráter conciliatório, e de busca de consenso entre os interesses em jogo. Institui o que conhecemos hoje por “educação básica”, compreendendo o ensino fundamental e o ensino médio como níveis obrigatórios de educação. Recentemente conhecemos a política que ampliou o ensino fundamental para 9 anos. Sem, contudo, garantir um valor percentual dos recursos públicos a serem destinados às unidades educativas do sistema e sem aprofundar a discussão sobre a valorização do magistério e a qualidade social e pedagógica da escola, a atual LDB se confronta com 
uma realidade educacional contraditória, composta de 15 milhões de analfabetos com mais de 15 anos, com o aumento exponencial da repetência e do abandono escolar, com a falta de estrutura e sucateamento das escolas e com um processo de precarização cada vez maior das condições de trabalho docente, especialmente nas zonas rurais e periferias das grandes cidades.

Desta rápida incursão, o que podemos observar, como já afirmamos, é a constituição de um sistema seletivo e dualista, que promove exclusão, desigualdade e atraso, na medida em que, a partir dele, se constroem percursos distintos de entrada e saída da escola, que 40\% dos jovens não concluem o Ensino Médio, que o acesso à educação é diferente conforme a renda, que o grau de aproveitamento da escolarização depende muito mais da formação e das estratégias familiares em relação à educação de seus filhos que do projeto pedagógico da instituição, entre outros aspectos.

Como se não bastasse o tardio, frágil e insuficiente movimento pela efetivação da escola pública e da democratização do sistema educativo brasileiro, hoje observamos, perplexos, não a continuidade deste movimento, mas um claro projeto de desmonte do sistema público de educação - se é que podemos dizer, a rigor, que algum dia tenha existido um sistema público de educação no Brasil. Algumas escolas, especialmente as escolas rurais e aquelas localizadas em territórios precarizados, zonas de risco, vulnerabilidade e violência, foram completamente abandonadas pelo Estado, o que se evidencia pela falta de investimento, recursos e infraestrutura, os quais só chegam à escola mediante a participação das unidades educativas em programas e projetos oferecidos pelos poderes públicos (municipal, estadual e federal), muitos dos 
quais criados e implementados em nome da eficiência, da eficácia e da elevação dos índices de "qualidade" da educação brasileira nos programas internacionais de avaliação, a exemplo do PISA.

$\mathrm{O}$ fato é que, historicamente, o Estado Brasileiro nunca se ocupou, efetivamente, do sistema público de educação até muito recentemente, de modo que a via do ensino privado apareceu como única opção para as famílias favorecidas economicamente e para as elites dominantes em sua autoformação e perpetuação como classe dirigente. Já a rede pública, desenvolvendo-se muito lentamente, ainda convive com enormes problemas quantitativos e qualitativos. É assim que se constitui o sistema educacional brasileiro, fragmentado e estruturado em duas redes díspares e diametralmente opostas em termos de objetivos, estrutura e funcionamento.

Por esse motivo, o sistema brasileiro comporta, com acentuado contraste, de um lado, uma formação científica, rigorosa, de alta qualidade, pela via da rede privada, voltada aos filhos das classes dominantes para que se perpetuem enquanto classes dirigentes. Estarão eles a ocupar a maioria das vagas das universidades públicas brasileiras, ou mesmo das melhores e mais renomadas universidades privadas, tendo em vista a continuidade da trajetória escolar previamente definida pela sua condição social, em nome da qual se configuram os quadros profissionais melhor remunerados no mercado de trabalho. De outro lado, uma escolarização básica de baixa qualidade, em escolas precárias, com professores mal remunerados, na rede pública, respondendo à trajetória escolar das camadas desfavorecidas da sociedade. Neste caso, quando não interrompida, a escolarização dos filhos da classe trabalhadora segue pela via da formação técnica e profissionalizante, quando muito, ascendem à formação superior nas universidades privadas de pior 
qualidade, o que lhes permite, não menos, ocupar um lugar subalterno, enquanto classe dominada, no mundo da produção.

As respostas, em termos de políticas públicas, que têm sido dadas às desigualdades de origem, tanto sociais como escolares, constituem assunto de interesse entre muitos estudiosos da educação. Em nosso caso, identificamos que a ausência de um sistema educacional universal e democrático, que reserve o direito à educação de qualidade a todos, tem favorecido, em contrapartida, políticas e iniciativas compensatórias neste âmbito, a exemplo do Programa Universidade Para Todos (Prouni) ${ }^{4}$, acima evocado. Ao invés de uma política rigorosa de universalização da escola e da universidade, em todos os níveis, que articule formação de educadores, financiamento público fixo, gestão democrática das instituições, estrutura e instalações adequadas e uma rede de parceiros e serviços públicos complementares atuando em conjunto com as unidades educativas, o que temos são projetos e programas acessórios, temporários e focalistas, preocupados tão somente em atenuar as graves contradições que comprometem a educação da sociedade brasileira, isso para não mencionar a transferência de responsabilidade do Estado com a educação escolar para Organizações Não Governamentais ou ainda para a Iniciativa Privada. Sem um sistema de educação público, gratuito, universal, de qualidade, para todos, não é possível confrontar as desigualdades de partida.

Por outro lado, afirmar que as desigualdades escolares decorrem das desigualdades sociais - o que não deixa de ser verdade -, embora explique a causa do problema e ajude a denunciar os aspectos estruturais que geram e multiplicam as injustiças e disparidades educacionais em nosso país, não é suficiente para pensarmos o que a escola pode fazer, ou em que medida ela pode contri- 
buir para a luta contra as desigualdades, já que se a escola não pode tudo, talvez algo ela possa fazer.

Não podemos, portanto, negligenciar as diferentes formas e expressões das desigualdades sociais e escolares que são produzidas em articulação com as trajetórias de fracasso e sucesso escolar, a depender das experiências absorvidas no contexto social de origem, e que impactam nas continuidades e descontinuidades, escolhas e orientações profissionais mobilizadas pelas relações tecidas também dentro da escola ou por meio das políticas educacionais aí implementadas. Eis aí um campo fértil para a atuação da escola a partir de seu projeto político pedagógico e de um competente trabalho docente e institucional.

Tendo como pano de fundo uma concepção de educação que consagra a escola pública como prioridade do Estado, ou seja, que atribui à escola um caráter ético, social, cultural e político de grande envergadura, posto que a escola é um direito e um processo sistemático pelo qual todas as crianças e jovens devem ter acesso aos conhecimentos historicamente produzidos, os artigos aqui reunidos pretendem, cada qual ao seu modo, abordar um ou outro aspecto da relação entre escolarização, formação e políticas públicas, no intuito de denunciar como as desigualdades sociais a escolares vêm sendo produzidas, retificadas e/ou negligenciadas.

O artigo de Jéferson Silveira Dantas e Célia Regina Vendramini, por exemplo, trata justamente uma das polêmicas questões que mencionamos acima: a articulação entre escola pública, organizações não governamentais e o aparato estatal. Os autores argumentam, a partir da experiência do Fórum do Maciço do Morro da Cruz, em Florianópolis (SC), que a escola entra em uma relação desfavorável com o chamado “Terceiro Setor”, na medida em que os 
movimentos sociais nos quais se vê engajada perdem cada vez mais força política e visibilidade social diante do crescimento e valorização das ONGs pelas atuais políticas neoliberais, sobretudo em territórios de precariedade e em contextos de vulnerabilidade social.

Entrando no universo das desigualdades concretamente vistas e sentidas, o texto de Maria dos Anjos Viella e Soraya Franzoni Conde problematiza a suposta redução, proclamada pelo Governo Federal, do trabalho infantil no Brasil e em Santa Catarina, argumentando que tal redução torna-se enganosa se não considerada a ampliação e a diversificação das atividades desenvolvidas pelas crianças no atual contexto. Decorrentes das transformações do mundo do trabalho e das atuais formas de trabalho coletivo, as crianças se envolvem com atividades invisíveis à fiscalização, o que nos coloca inúmeros desafios para pensarmos e enfrentarmos as novas relações entre trabalho, educação e desigualdades sociais.

O estudo de caso sobre as escolas públicas do campo, realizado por Adriana D’Agostini e Mauro Titton, revela um dos problemas nodais da construção das desigualdades sociais e escolares em nosso país. Como dissemos anteriormente, as populações do campo foram, historicamente, desconsideradas pelas iniciativas governamentais e políticas públicas voltadas ao processo de escolarização. Nem mesmo as leis e diretrizes educacionais nacionais conseguiram contemplá-las, como se elas não fossem parte da sociedade brasileira. Na verdade, conforme explicam os autores, trata-se de uma relação que se inicia com a subordinação do campo à cidade e que, hoje, se aprofunda com o abandono e as condições de precariedade em que se encontram as escolas do campo, apesar de existirem possibilidades de transformação anunciadas em seus projetos pedagógicos orientadores. 
A relação entre campo e cidade, escola e vida, é o tema do artigo de Caroline Bellaguarda de Azevedo, Célia Regina Vendramini e Fabiane Marra da Silva Pereira Garcia. Ao abordarem experiências escolares situadas no campo e na cidade, em suas singularidades, mas também em suas similaridades, as autoras discutem os limites da escola e da vida no atual contexto social marcado por profundas desigualdades.

Invertendo o caminho em direção às experiências educativas em sua expressão qualitativa, Ridha Ennafaa explora um conjunto de dados voltados ao tratamento das desigualdades sociais e escolares no Brasil. O autor procura, então, superar o desafio de "medir" a redução das desigualdades, tomando como exemplo o ensino superior brasileiro, em particular o acesso dos estudantes à Universidade Federal do Rio Grande do Norte. Ao cruzar dados gerais sobre a educação superior no Brasil com dados individuais dos estudantes, o autor observa que a análise das desigualdades escolares varia conforme a hierarquia existente entre os cursos, as opções dos estudantes, bem como o desempenho destes, fatores que interagem diretamente com as políticas de inclusão em vigor.

Desigualdades sociais e educação escolar é o eixo da reflexão proposta por Suze Scalcon em seu artigo. Contextualizando tal temática no âmbito da reestruturação produtiva do capital, a autora interroga o pressuposto da desigualdade natural entre os homens como substrato da sociedade de mercado, discutindo noções como "diferença" e "desigualdade" que, tratadas como semelhantes e assim povoando o debate sobre a educação e a escola na atualidade, acabam por confundir e reforçar a produção de desigualdades.

Finalmente, o texto de Justina Inês Sponchiado aborda a problemática das desigualdades sociais e escolares do ponto de vista da 
política educacional. A autora discute as controvérsias da política que implementou o ensino fundamental de 9 anos, ao mesmo tempo que a confronta com a avaliação dos pais e familiares das crianças diretamente afetadas, destacando os processos de exclusão desencadeados entre aqueles que, contraditoriamente, mais apostam na escola, uma vez que as famílias de baixa renda não dispõem de outro modo de acesso ao conhecimento além da escola pública.

Como se vê, o tema das desigualdades sociais e escolares configura um amplo e largo problema de estudos e pesquisa na medida em que diversas abordagens, delimitações e pontos de vista são possíveis. Por outro lado, trata-se de um problema denso e complexo, haja vista a necessidade de apreensão do fenômeno da desigualdade em sua profundidade, em sua totalidade, em seu movimento histórico, com suas contradições, e em suas diferentes manifestações e em suas expressões atuais. Interrogar, problematizar, conhecer e enfrentar o problema das desigualdades sociais e escolares no Brasil exige, de nossa parte, explicitar os interesses em jogo e assumir compromissos.

Esperamos que o debate aqui proposto pelo conjunto dos textos, além de contribuir para um melhor posicionamento dos sujeitos coletivos na disputa pela hegemonia no/do campo educacional, ajude também a elucidar algumas questões delicadas que vêm permeando o debate sobre a educação e a escolarização desde os primeiros movimentos pela democratização da escola brasileira: a produção e reprodução das desigualdades, no campo e na cidade, da educação infantil ao ensino superior, enfim, no coração das relações sociais, políticas e pedagógicas que atravessam o nosso sistema educativo.

Boa leitura! 


\section{Notas}

* Doutora em Educação pela Unicamp, docente do Centro de Ciências da Educação da UFSC, integrante do Núcleo de Estudos e Pesquisas sobre as Transformações do Mundo do Trabalho (TMT/UFSC) e coordenadora adjunta do OESC - Observatório da Educação de Santa Catarina (CED/UFSC).

** BUARQUE, Cristovam. A revolução republicana na educação.

${ }^{2}$ Para maiores informações, consultar minha tese de doutorado intitulada "Movimentos e ideias sobre educação comunitária no Brasil: matrizes filosóficas e desdobramentos históricos no século XX", defendida junto à Faculdade de Educação da Unicamp, em 2009.

${ }^{3}$ SAVIANI, Dermeval. História das ideias pedagógicas no Brasil.

${ }^{4} \mathrm{O}$ Prouni " [...] tem como finalidade a concessão de bolsas de estudo integrais e parciais em cursos de graduação e sequenciais de formação específica, em instituições privadas de educação superior. Criado pelo Governo Federal em 2004 e institucionalizado pela Lei $n^{\circ}$ 11.096, em 13 de janeiro de 2005, oferece, em contrapartida, isenção de alguns tributos àquelas instituições de ensino que aderem ao Programa." Para maiores informações, consultar: <http:// prouniportal.mec.gov.br>. 
